Original Article

\title{
ANTIEMETIC ACTIVITIES OF INDONESIAN STINGLESS BEE PROPOLIS ON EMETIC INDUCED BY ANTI-TUBERCULOSIS DRUGS
}

\author{
MAHANI ${ }^{a *}{ }^{*}$, FIRMANSYAH FATURACHMANa, MICHELLEa, ELAZMANAWATI LEMBONGa ${ }^{a}$, AHMAD SULAEMAN ${ }^{b}$, \\ HARDINSYAHb, NUNUNG NURJANAH', SUNARNOc, KAMBANG SARIADJIc
}

aFood Technology Department, Faculty of Agric, Industrial Technology, Universitas Padjadjaran, Indonesia, bcommunity Nutrition Department, Faculty of Human Ecology, IPB University, Indonesia, cNational Institute of Health Research and Development, Indonesian Ministry of Health Indonesia

Email: mahani2018@unpad.ac.id

Received: 03 Sep 2020, Revised and Accepted: 13 Feb 2021

ABSTRACT

Objective: This study aims to determine the antiemetic potential of stingless bee propolis in reducing the prevalence of nausea due to consumption of Anti-Tuberculosis Drugs (ATD) in Tuberculosis patients and to identify phytochemical compounds that act as an antiemetic in propolis.

Methods: The stingless bee propolis used was Wallacetrigona incisa from South Sulawesi. The clinical testing used the randomized controlled trial, randomization using permuted block randomization consisting of one positive control group and two treatment groups. The active components analyzed using Gas Chromatography-Mass Spectrometer (GC-MS) pyrolyzer.

Results: This study found that the measurement at week 0 obtained the mean value of nausea per week for each group P0 (Placebo), P1 (Propolis 6\%), and P2 (Propolis 30\%) were respectively 2.14; 1.5 and 5.2 events/week, at week 8 the prevalence of nausea by 2.0; 1.0 ; and 1.6 events/week, and week 24 the prevalence of nausea by 3.0; 0; and 0 events/week. There are 11 compounds with concentrations above $1 \%$ that act as antiemetic compounds either through direct and indirect mechanism with a total concentration reaches $75,47 \%$.

Conclusion: Based on all determinant parameters, propolis of Wallacetrigona incisa species from South Sulawesi has antiemetic activity and can reduce the prevalence of emetic induced by ATD consumption in pulmonary TB patients.

Keywords: Antiemetic, Antiemetic Compounds, Anti-Tuberculosis Drug, Stingless Bee Propolis, Nausea

(C) 2021 The Authors. Published by Innovare Academic Sciences Pvt Ltd. This is an open access article under the CC BY license (https://creativecommons.org/licenses/by/4.0/) DOI: https://dx.doi.org/10.22159/ijpps.2021v13i4.39618. Journal homepage: https://innovareacademics.in/journals/index.php/ijpps.

\section{INTRODUCTION}

Pulmonary tuberculosis (TB) is an infectious pulmonary disease that is still prevalent in Indonesia. In 2018, 570.289 pulmonary TB cases were recorded and treated in Indonesia, with an estimated mortality index of $12 \%$ [1]. Infection of pulmonary TB is caused by Mycobacterium tuberculosis (MTB), is a pathogenic bacteria that can live and multiply inside and outside phagocytic cells so that the process of forming a bacterial colony is difficult to control and resist [2].

TB control in Indonesia started in 2000 by implementing the DOTS (Directly Observed Treatment Short-course) strategy. This strategy is a treatment step using anti-TB drugs (ATD), which consists of a combination of several types of drugs that are effective in treating TB [3]. Combining ATD is considered effective but has side effects, such as nausea, vomiting, and appetite loss [4]. The effects will decrease a patient's nutritional intake and worsen the patient's nutritional status, which causes a longer recovery process [5]. The condition of nausea and vomiting can be minimized by administering an antiemetic compound (anti-nausea) and one of the products proven to have antiemetic properties is propolis [6, 7]

Propolis is a resin that is produced by bees and used as a hives building material. Propolis is formed from plant origin collected and processed by bees with the addition of various natural enzymes and saliva in their bodies [8]. Stingless bees produce propolis as a form of self-defense so that it produces more propolis than other species. Stingless bees propolis also has a high flavonoid content which made bees of this species more widely cultivated as propolis producers [9, 10]. Phytochemical compounds in the form of flavonoids and phenolics in propolis can play an active role as antioxidants, antimicrobials, antiseptics, and antiemetic $[6,11,12]$.

The study on the benefits of propolis as antiemetic is still minimal, but Fikri et al. [6] conducted an antiemetic test of Indonesian propolis on chicks given $\mathrm{CuSO}_{4}$ and reported that Indonesian propolis reduced symptoms of nausea and has a similar effect with antiemetic power of metoclopramide (an anti-nausea drug). Induction of $\mathrm{CuSO}_{4}$ in chicks will stimulate the irritated stomach wall that causes nausea and vomiting mechanisms. These mechanisms also occur in humans so that they are suitable for modeling the potential antiemetic of a compound or product [13]. The finding triggered to develop propolis as an antiemetic for humans, Sulaeman et al., which states that propolis has the potential to reduce nausea and vomiting in pregnancy [11]. Therefore, this study is important to determine the antiemetic potential of stingless bee propolis in reducing the prevalence of nausea due to consumption of ATD in TB patients and to identify phytochemical compounds antiemetic in propolis.

\section{MATERIALS AND METHODS}

\section{Materials}

The material used in this study was propolis originating from South Sulawesi in stingless bees Wallacetrigona incisa which was harvested by a group of farmers and obtained through the intermediary CV. Nutrima Sehatalami, Bogor. The use of these samples is based on the active compound, IC50, and the propolis's toxicity has the best cumulative index value among other propolis in Indonesia [11, 12].

\section{Propolis extraction}

The method of extraction propolis was from patent no. P00201100811 in 2011 about short, productive, and efficient extraction method in the production of liquid propolis.

First, $1 \mathrm{~kg}$ raw propolis (still in the glass transition process) was cut to a smaller size, then mixed with $70 \%$ ethanol with a ratio $1: 2,5$ (propolis: ethanol). This process was carried out at room temperature to avoid damage to propolis due to high temperatures. Then, propolis was mashed into propolis pulp and filtered using a 
30-mesh filter before being left for $12 \mathrm{~h}$. The filtrate was separated while the rest of the propolis pulp was mixed with ethanol $70 \%$ at a ratio of 1: 1,5 (propolis: ethanol) and was mixing for 5 min.

The next step was the evaporation of filtrate using a rotary vacuum evaporator connected to a vacuum pump with a pressure $4 \mathrm{kPa}$ rotation pump $3 \mathrm{rpm}$, at $50{ }^{\circ} \mathrm{C}$. When the ethanol had evaporated out, the filtrate colours turned into light-brown and turned into dark-brown until the remaining water had evaporated. The result of this filtrate was a dark-brown extract of propolis. After that, the propolis extract was added with propylene glycol and was filtered using Whatman paper no. 50.

\section{Clinical testing}

The design used was a randomized controlled trial, randomization using permuted block randomization [14], consisting of one positive control group and two treatment groups. Intervention and testing were carried out in a double-blind manner (both the investigator and the subjects were unaware of the treatment given). The subject size was determined according to the sample size table in a controlled clinical trial [15]. Based on the table, assuming a significance level of $\alpha 0.05$ and a power of $80 \%$, the minimum sample size is 13 subjects per group. The samples used 50 subjects to ensure data security and validity.

The criteria for the research subjects were as follows: a) Inclusion criteria: TB patients, aged 12-45 y (adolescents-adults), willing to participate in the study by signing informed consent; b) Exclusion criteria: smoking, suffering from hepatitis or other diseases that interfere with the study, drinking alcohol, pregnant, breastfeeding, using contraceptives, taking other drugs or herbs or supplements, and TB patients recurring.

The propolis dose in the subject was carried out with an approach as a companion drug for ATD. The positive control group was given a companion in the form of propylene glycol liquid placebo. The dose determination of treatment group one was based on the clinical dose of Pranandaru et al. (2011), were 3 drops of propolis (20\% concentration) in TB patients, the dose given for group one was twice from the reference dose by administering 20 drops of propolis (6\% concentration) [16],. The dose given for group two was 30 drops of propolis ( $30 \%$ concentration), was equivalent to five times the dose for group one and was still lower than the clinical dose of Liu et al. (2013), 103,2 drops of propolis. This method used an equalization of the number of propolis droplets of 20 drops in one use; one drop of propolis was equivalent to $0,028 \mathrm{ml}$ assuming a 6 $\mathrm{ml}$ volume eye drop bottle (20 drops $\approx 0.56 \mathrm{ml}$ ) [17]. The propolis had given every day for $56 \mathrm{~d}$ ( 2 mo early in the intensive phase of pulmonary TB treatment with ATD, then follow-up control was carried out of given propolis 3 times a week for $16 \mathrm{w}$ (the next stage of pulmonary TB treatment with ATD).

The incidence of nausea was observed for 6 mo with data retrieval 3 times, namely during the first week of initial intervention (W0), the intensive transition period to the advanced stage (W8), and the last week of intervention (W24).

All clinical experiments were carried out under ethical approval from the Health Research Ethics Committee, Faculty of Medicine of University of Indonesia number: 1036/UN2. F1/ETIK/2015.

\section{GCMS (Gas Chromatography Mass Spectrometry) analysis}

This study used Shimadzu GCMS-QP 2010 with pyrolysis, with the carrier gas is in the form of Helium UHP, rt x $5 \mathrm{~ms}$ column. The column oven temperature was set to $50{ }^{\circ} \mathrm{C}$ for $5 \mathrm{~min}$, then gradually increase to $280{ }^{\circ} \mathrm{C}$. The temperature injection pressure was set at $101 \mathrm{kPA}$ with column flow $0,85 \mathrm{ml} / \mathrm{min}$. MS detector was set at ion source temperature $\left(200^{\circ} \mathrm{C}\right)$, interface temperature $280^{\circ} \mathrm{C}$, detector temperature $280^{\circ} \mathrm{C}$, pyrolyzer temperature $300{ }^{\circ} \mathrm{C}$. When stable, 1 $\mu \mathrm{g} / 1$ drop liquid propolis was injected into the pyrolyzer, and GC-MS worked automatically. The process of determination took $50 \mathrm{~min}$, and the results of chromatogram were stored on a computer. The active compounds of propolis were identified using the Willey standard and Nist Libraries on GCMS data system.

\section{Phytochemical screening}

Phytochemical screening was to examine the active compounds of propolis which acts as antiemetic. The chromatogram from the GCMS pyrolysis results contains information about active compounds of propolis sample. Furthermore, a literature study was carried out to find the biological activity or mechanism of each active compound's action, from in vitro, in vivo, and clinical research. The GC-MS chromatogram was compared to literature studies to find every active compound of propolis that could reduce the prevalence of nausea during ATD consumption.

\section{RESULTS AND DISCUSSION}

\section{Effects of propolis on the prevalence of nausea}

Nausea is a symptom that can be used as an indication or response to the presence of toxic compounds that enter the body $[18,19]$. The sensation of nausea can be suppressed or eliminated through phytochemical compounds with antiemetic activity [13]. As an ATD companion, performed to reduce nausea and vomiting symptoms due to side effects of pulmonary TB treatment using ATD. The results of the measurement of the average prevalence of nausea are presented in fig. 1.

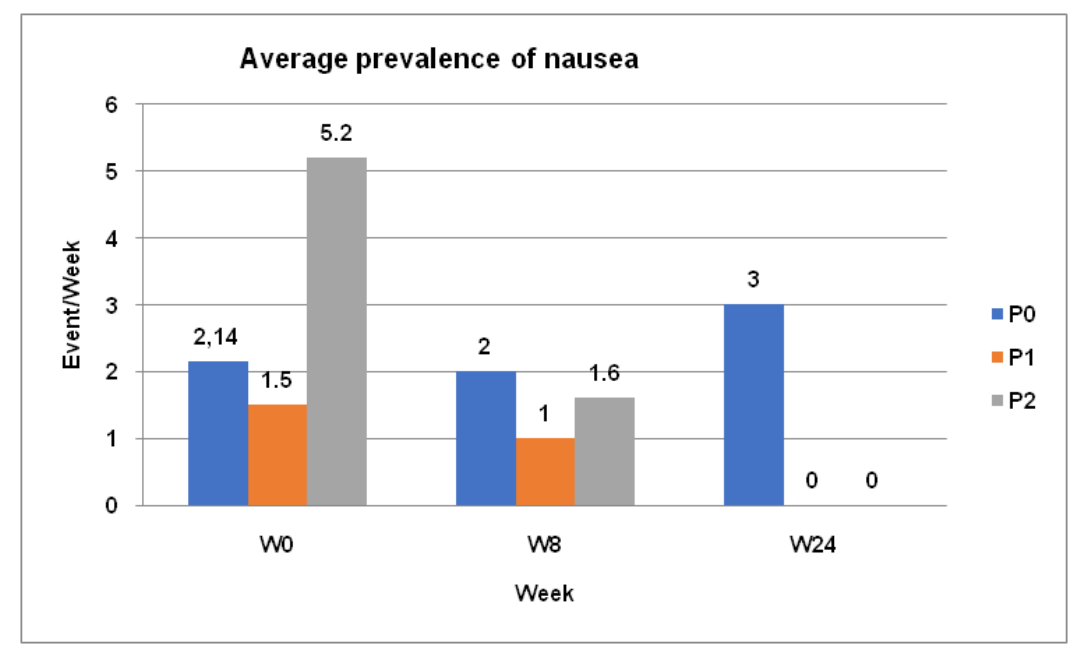

Fig. 1: Changes in average prevalence of nausea

Based on the results of the graph in fig. 1., the measurement at week 0 obtained the mean value of nausea per week for each group P0, P1, and P2 were respectively $2.14 ; 1.5$ and 5.2 events/week. Variation of data on P2 value has the highest number compared to other groups, 
the difference in data is considered normal. The grouping of research subjects has been carried out evenly by using permuted block randomization methods based on the sex and age of the patient so that the response that appears has a low level of bias for confounding variables $[15,20]$

Measurement of the 8th week of all treatment groups decreased the prevalence of nausea by $0.14 ; 0.5$; and 3.6 events/week for groups P0, P1 and P2. Based on these data, the P2 group until the end of the intervention (propolis supplementation), namely at week 24th showed the greatest decrease until it reached a value of 0 incidents of nausea/week, followed by group P1, which also experienced a decrease to a value of 0 incidents of nausea/week, while the group $\mathrm{P} 0$ has increased the prevalence of nausea/week.

The increase in the prevalence of nausea in the P0 group is an indication of the presence of toxic compounds from ATD that accumulate in the digestive tract, plasma, and even Cerebrospinal fluid (CSF) $[18,19,21]$. These toxic compounds come from the consumption of ATD, first-line ATD (Isoniazid, Rifampicin, Pyrazinamide, and Ethambutol) are cytotoxic drugs; these properties are needed to destroy MTB cell [22, 23]. Its presence in the body as a toxic compound often causes side effects such as nausea, vomiting, indigestion, and others [22, 24].

This can be severe due to allegations of liver injury resulting from the consumption of hepatotoxic ATD [25]. Consumption of ATD for a long time will cause the accumulation of toxic compounds resulting in chronic toxicity conditions and lead to liver injury [21]. Liver injury will have an impact on the reduction of liver function as a detoxifying organ and will cause symptoms of nausea and vomiting if exposed to toxic compounds and accumulation of toxic compounds $[19,21,26,27]$. Isoniazid, rifampicin and pyrazinamide are hepatotoxic drugs, the metabolism of these compounds is carried out in the liver with the help of the body's natural enzymes [22].

Isoniazid is the most toxic drug in the first-line ATD, because isoniazid is a toxic compound both from its function as a radical compound that destroy Tb cells and in terms of its intermediate metabolites which are more toxic and capable of damaging liver cells [22, 24, 26]. Rifampicin is a toxic compound that is easily detoxified by the liver, but when combined with isoniazid, rifampicin will cause an increase in the level of toxicity to the liver $[22,23,26]$. Meanwhile, pyrazinamide is the most hepatotoxic drug because of its use, it causes more symptoms of liver damage than other drugs, and it is even recommended to be replaced by a combination of first-line ATD [28].

The phenomenon of increasing the prevalence of nausea caused by liver damage has attracted the attention of researchers because apart from having antiemetic activity, Indonesian propolis also function as a hepatoprotector. The active compounds in propolis are able to protect the liver from the toxic effects of ATD $[11,29]$. Therefore, liver damage can be anticipated, so that the function of the liver as a detoxification organ is not disturbed and the incidence of emesis can decrease.

The final results of the observation group P1 and P2 experienced a decrease when compared to before the intervention, the value of the decrease was 1.5 and 5.2 incidents of the nausea/week, while the P0 group experienced an increase of 0.86 incidents of the nausea/week. Thus,the P2 group experienced the greatest decrease in the prevalence of nausea and vice versa, the P0 group experienced an increase in the prevalence of nausea. This shows that the treatment of propolis supplementation with a concentration of $6 \%(\mathrm{P} 1)$ and $30 \%$ (P2) against TB patients who consume ATD has an antiemetic effect.

\section{Antiemetic compounds propolis wallacetrigona incisa from south sulawesi}

Identification of the active compound of ATD complementary propolis was carried out using the GCMS pyrolysis and found about 100 constituent compounds. These compounds are phytochemical compounds which are derivatives of polysaccharide compounds, lipopolysaccharides and amino polysaccharides. The identification of active antiemetic compounds will only be carried out on compounds with concentrations above $1 \%$, with the consideration that the consumption of propolis as a complement to ATD is only 20 drops (equivalent to $0.56 \mathrm{ml}$ ) so that the concentration is considered too low. In addition, compounds with a concentration of $<1 \%$ have not much known biological activity, although there is a possibility that they may have a direct antiemetic activity or a synergistic relationship with other compounds.

There are 16 compounds with concentrations above $1 \%$ with a total concentration of $84.46 \%$. The list of active compounds along with their concentrations and biological activities, are shown in detail in table 1 . The function of these compounds has been further identified, especially their role as antiemetic by the literature study method. The functions of these compounds were investigated, especially as an anti-emetic by means of literature studies. Based on the results of the literature study, it was found that 16 compounds had a concentration of $>1 \%$, and as many as 11 compounds had antiemetic activity either directly or indirectly, 1 compound had biological activity other than antiemetic and 3 compounds had no biological activity. Compounds that have antiemetic activity include: (1) Methyl- $\alpha$-d-glucopyranoside, (2) 5-Azulenemethanol, 1,2,3,3a, 4,5,6,7octahydro-alpha. alpha, 3, 8-tetramethyl, (3) 1,2,3-Propanetriol, (4) Hexadecanoic acid, (5) Ethyl Ester 3-Hydroxy-Tridecanoic Acid, (6) 2,6-Dimethoxyphenol, (7) Pentadecanoic acid, 14-methyl-, methyl ester, (8) 1,6-Anhydro-Beta-D-Glucopyranose, (9) (2S, 3R)-3-Allyl-3methylapfelsaure-4-ethylester, (10) 1,4, 5-Trimethylnaphthalene, (11) Tetradecanoic acid. Compounds that have biological activity are: Isosorbide. Meanwhile, 3 compounds that have not been found with biological activity are: (1) 2-Methoxyethyl acetate, (2) 8-Oxabicyclo [5.1.0] octane, (3) Dimethyl 2-hydroxy-2-methylbutane-1,4-dioate.

The remaining 86 compounds had a concentration of $<1 \%$ with an accumulated concentration of $15.54 \%$. The amount of accumulated compound concentration $<1 \%$ causes the combination of compounds that might have the potential for antiemetic activity both in single compound function or in synergy interaction between compounds in propolis or in the body. The role of these compounds needs to be studied further because it can have an impact on the response to the prevalence of nausea. However, this study did not discuss each of these compounds due to the low concentration of each compound, which would raise questions about the benefits of significant and effective dosages.

Based on literature studies, propolis of Wallacetrigona incisa from South Sulawesi have antiemetic activity through two mechanisms: (1) Direct antiemetic mechanism in the form of compounds that are inhibitors of 5-HT4 stimuli, (2) Indirect antiemetic mechanism by inducing compounds in the body that capable of suppressing emetic.

The direct antiemetic mechanism is based on the research of Eda et al. [7] stated that it was found that the antiemetic activity of propolis was caused by terpenoid and flavonoid group compounds. In propolis Wallacetrigona incisa from South Sulawesi was found 2 compounds belong to the group of compounds, namely: 5Azulenemethanol, 1,2,3,3a, 4,5,6,7-octahydro-alpha. alpha, 3,8tetramethyl (terpenoids), and Methyl- $\alpha$-d-glucopyranoside (flavonoids). Both compounds have a total concentration of $38.35 \%$ $(36.13+2.22)$.

5-Azulenemethanol, 1,2,3,3a, 4,5,6,7-octahydro-alpha. alpha, 3,8tetramethyl compound or better known as bulnesol compound which is a terpenoid group of sesquiterpene types founded in seasonings, spices and essential oils from tree wood, especially of ferula species. Bulnesol is strongly thought to provide a protective effect on the stomach and reduce gastrointestinal hyperactivity. This assumption is based on the research of Eda et al. [7] who found the use of terpenoid compounds in Brazilian propolis extracts that we're able to reduce retching in chicks given nausea agents. According to Ahmed et al. [13] the induction nausea agents in chicks can trigger emesis through the stimulus of the stomach wall through stimulation of 5-HT4, a natural compound terpenoid such as sesquiterpenes and triterpenes are thought to be able to inhibit 5HT4 stimuli. This mechanism is one of the mechanisms that also causes nausea and vomiting in humans. Apart from having a similar mechanism, this model is also suitable for evaluating the involvement of the brain in the emergence of emetic [37]. Another function of bulnesol along with their isomeric components, namely guaiol has biological activity as an antimicrobial compound [38], and 
Table 1: Active compounds of propolis W. Incisa detected using GCMS Pyrolysis

\begin{tabular}{|c|c|c|c|c|c|}
\hline No. & Compound name & RT & Concentration (\%) & Antiemetic activity & Type of mechanism \\
\hline 1 & 2-Methoxyethyl acetate & 8.510 & 1.16 & - & - \\
\hline 2 & 8-Oxabicyclo[5.1.0]octane atau Epoxycyloheptane & 12,942 & 2,16 & - & - \\
\hline 3 & 1,2,3-Propanetriol (gliserol) & 13,396 & 6,45 & {$[30,31]$} & 2 \\
\hline 4 & Isosorbide & 15,129 & 1,5 & - & - \\
\hline 5 & Ethyl Ester 3-Hydroxy-Tridecanoic Acid (C13) & 16,333 & 2,06 & [14] & 3 \\
\hline 6 & 2,6-Dimethoxyphenol & 16,392 & 1,67 & [32] & 3 \\
\hline 7 & Methyl- $\alpha$-d-glucopyranoside (flavonoid) & 16,741 & 1,33 & [7] & 1,3 \\
\hline 8 & 1,6-Anhydro-Beta-D-Glucopyranose (Levoglucosan) & 18,166 & 4,44 & [33] & 3 \\
\hline 9 & $\begin{array}{l}(2 S, 3 R)-3-\text { Allyl-3-methylapfelsaure-4-ethylester } \\
\text { (allicin) }\end{array}$ & 18,436 & 2,50 & {$[34,35]$} & 3 \\
\hline 10 & $\begin{array}{l}\text { 5-Azulenemethanol, 1,2,3,3a,4,5,6,7-octahydro-. } \\
\text { alpha.,. alpha.,3,8-tetramethyl (Sesquiterpen) }\end{array}$ & 18,517 & 2,22 & [7] & 1,3 \\
\hline 11 & 1,4,5-Trimethylnaphthalene & 18,625 & 1,83 & {$[36]$} & 3 \\
\hline 12 & Methyl. alpha.-D-glucopyranoside (flavonoid) & 19,158 & 34,80 & [7] & 1,3 \\
\hline 13 & Dimethyl 2-hydroxy-2-methylbutane-1,4-dioatee & 19,442 & 4,17 & - & - \\
\hline 14 & Tetradecanoic acid (Miristic acid; C14) & 19,542 & 13,92 & [14] & 3 \\
\hline 15 & Pentadecanoic acid, 14-methyl-, methyl ester & 20,343 & 3,02 & {$[14]$} & 3 \\
\hline \multirow[t]{2}{*}{16} & Hexadecanoic acid & 20,908 & 1,23 & {$[14]$} & 3 \\
\hline & Total Concentration of Antiemetic Compound & & 75,47 & & \\
\hline
\end{tabular}

Details: 1) 5-HT 4 stimulus inhibition 2) induction of glycerol kinase 3) hepatoprotector

Methyl- $\alpha$-d-glucopyranoside is a sugar/glucoside compound that belongs to the flavonoid group. Among all the active compounds detected by GC-MS pyrolysis, this glucoside compound is the main component of Wallacetrigona incisa propolis because it has the highest concentration of $36.13 \%(1.33 \%+34.80 \%)$. As the main component, Methyl- $\alpha$-d-glucopyranoside has various biological activities: anti-tuberculosis [42], antibacterial [43], antifungal [44], antitumor [45], antivirals [46], and antiemetic [7]. Glycosides are strongly thought to have a protective effect on the stomach and reduce gastrointestinal hyperactivity. This assumption is based on the research of Eda et al. [7], which found flavonoid in the Brazilian propolis extract that was able to reduce retiching in chicks given nausea agents. Due to its high concentration and various biological activities, the presence of Methyl- $\alpha$-d-glucopyranoside as the main composition of propolis is able to make propolis as a nutritional companion of ATD, which is effective in suppressing symptoms of emesis and in the treatment of pulmonary TB.

The indirect antiemetic mechanism is based on the identification of compounds capable of inducing other compounds in the body, the compounds that are induced have a function in reducing and even eliminating the incidence of emetic. Based on this, there are two mechanisms that can occur, the mechanism for the formation of the enzyme glycerol kinase and the hepatoprotective. The mechanism for the formation of the glycerol kinase enzyme as a compound to prevent nausea and vomiting is carried out by glycerol compounds [30,47], while the hepatoprotective mechanism is carried out by compounds that have antioxidants and anti-inflammatory activity $[48,49]$.

1,2,3-Propanetriol or glycerol is a glyceride compound that makes up various fatty acids. The concentration of glycerol in propolis Wallacetrigona incisa from South Sulawesi based on GC-MS pyrolysis was $6.45 \%$. Glycerol is able to prevent nausea and vomiting indirectly by inducing the formation of the enzyme glycerol kinase in the body. The activity and the amount of the glycerol kinase enzyme in the body is strongly influenced by the amount of ATP and glycerol available in the body; the relationship is a positive correlation [50]. The presence of glycerol and glycerol kinase in the body plays a role in the gluconeogenesis metabolic pathway in the liver, which will produce glucose [31]. This process occurs when the body is deficient in glucose, glycerol kinase will carry out a phosphorylation reaction against glycerol with a source of phosphate originating from ATP to form glucose-forming intermediates $[31,50]$. According to Johnston et al. [51], the absorption of glycerol and the process of gluconeogenesis can be inhibited if there is damage to the liver. Thus, the hepatotoxicity caused by the consumption of ATD will cause a decrease in glycerol absorption and a decrease in the amount of the enzyme glycerol kinase. Deficiency of the enzyme glycerol kinase can cause nausea and vomiting symptoms [30, 31, 47].

Prevention of nausea and vomiting can be done through a hepatoprotective mechanism. The hepatoprotector in the liver will prevent deficiencies in liver function as a detox and metabolic organ and prevent depletion of important enzymes such as cytochrome P450 [11]. By maintaining the liver, the symptoms of emetic caused by liver injury and the present of toxic compounds in the body can be minimized. The hepatoprotective mechanism is generally carried out through protective measures by phytochemical compounds that have antioxidant and anti-inflammatory activity $[9,49]$. Antioxidant compounds will protect the liver from radical and toxic compounds produced by ATD such as ROS, n-hydrazine, acetylisoniazid and isonicotinic acid [22].

2,6-dimethoxyphenol [32], 1,6-anhydro-beta-d-glucopyranose [33], (2S, 3R)-3-Allyl-3-methylapfelsaure-4-ethylester [34, 35], 1,4,5trimethylnaphthalene [36] are tested to act as antioxidant and showed a reduction of radical compounds 2,2-diphenyl-1picrylhydrazyl (DPPH). These compounds are able to reduce radical metabolites by binding to them by donating electrons.

Lipid group compounds such as tridecanoic acid, tetradecanoic acid, pentadecanoic acid and hexadecanoic acid in propolis also have active functions that act as antioxidants. According to Zheng et al. the four fatty acids have the ability to reduce radical 2,2-diphenyl-1picrylhydrazyl (DPPH). The total concentration of compounds that act as hepatoprotectors (antioxidants) is 30.67\% [14].

The compound methyl- $\alpha$-D-glucopyranoside and 5-azulenemethanol, 1,2,3,3a, 4,5,6,7-octahydro-alpha, alpha, 3,8-tetramethyl, in addition to acting as antiemetics compound directly, both compounds also function as antioxidants and can act as hepatoprotectors by reducing radical metabolites [11, 52]. This is supported by the results of research by Kokanova-Nedialkova et al. [53] and Vinholes et al. [54] which showed that these two compounds had a strong ability to reduce radical 2,2-diphenyl-1-picrylhydrazyl (DPPH).

Based on the concentration and mechanism of compounds that act as antiemetic, the percentage of antiemetic compounds either through direct and indirect mechanisms reaches $75.47 \%$ $(38.35 \%+6.45 \%+30.67 \%)$. This concentration is very large, even reaching $3 / 4$ of the total concentration of propolis. Based on the concentration of these antiemetic compounds, the propolis of Wallacetrigona incisa from South Sulawesi is very potential as an 
antiemetic product, supported by the effect of propolis in reducing the prevalence of emetic induced by ATD in pulmonary TB patients.

\section{CONCLUSION}

Propolis of Wallacetrigona incisa species from South Sulawesi has antiemetic activity and is able to reduce the prevalence of emetic induced by ATD consumption in pulmonary TB patients. Propolis concentration $30 \%$ showed better antiemetic activity than propolis concentration $6 \%$. There are antiemetic compounds with a total concentration of $75.47 \%$. The antiemetic mechanism occurs through three mechanisms: (1) Direct antiemetic mechanism in the form of inhibition of the $5-\mathrm{HT}_{4}$ stimulus which can trigger nausea and vomiting, (2) Indirect antiemetic mechanism by inducing the formation of the glycerol kinase enzyme which can suppress nausea and vomiting, (3) Indirect antiemetic mechanism by protecting the liver as a detoxifying organ for toxic compounds so that nausea can be avoided.

\section{ACKNOWLEDGEMENT}

The authors express gratitude to the Faculty of Agric. Industrial Technology of Universitas Padjadjaran for facilitating the research. Mahani as the principal investigator designed the research, directed the research, and wrote the paper. Firmansyah, Michelle and Elazmanawati help the research and wrote the paper. We are thankful to Ahmad Sulaeman and Hardinsyah for providing a method of propolis extraction, clinical testing, and active component of stingless bee propolis from South Sulawesi. We are also thankful to National Institute of Health Research and Development team, Nunung Nurjanah, Kambang Sariadji and Sunarno for providing the instrumental laboratory facilities to research and testing samples.

\section{FUNDING}

Nil

\section{AUTHORS CONTRIBUTIONS}

All the authors have contributed equally.

\section{CONFLICT OF INTERESTS}

The authors declare no conflict of interest associated with this study.

\section{REFERENCES}

1. WHO (World Health Organization). Country Profiles. OECD SME Entrep. Outlook; 2019. p. 189-249.

2. S Raghavan, P Manzanillo, K Chan, C Dovey, JS Cox. Secreted transcription factor controls mycobacterium tuberculosis virulence. Nature 2008;454:717-21.

3. Kementerian Kesehatan Republik Indonesia. Buku Pedoman Nasional Pengendalian Tuberkuolsis; 2014.

4. A Abbas. Monitoring efek samping obat anti-tuberkulosis (OAT) pada pengobatan tahap intensif penderita TB paru di kota makassar. J Agromed Med Sci 2017;1:19.

5. M Mahani, A Sulaeman, F Anwar, MRM Damanik, H Hardinsyah, A Ploeger. Efficacy of propolis supplementation to accelerate healing process and body weight recovery of pulmonary tuberculosis patients. J Gizi Dan Pangan 2018;1:1-10.

6. AM Fikri, A Sulaeman, SA Marliyati, M Fahrudin. Antiemetic activity of trigona spp. propolis from three provinces of Indonesia with two methods of extraction. Pharmacogn J 2018;10:120-2.

7. M Eda, Y Hayashi, K Kinoshita, K Koyama, K Takahashi, K Akutu. Anti-emetic principles of water extract of Brazilian propolis. Pharm Biol 2005;2:184-8.

8. VS Bankova, SL De Castro, MC Marcucci. Propolis: recent advances in chemistry and plant origin. Apidologie 2000;1:3-15.

9. N Kalsum, A Sulaeman, B Setiawan, IWT Wibawan. Phytochemical profiles of propolis trigona spp. from three regions in Indonesia using GC-MS. J Biol Agric Health 2016;14:31-7.

10. B Nurhadi, E Subroto, M Herudiyanto. Bee propolis trigona spp potential and uniqueness in Indonesia. Proceeding Univ Malaysia Teren Annu Sci; 2011.
11. A Sulaeman, AM Fikri, N Kalsum, M Mahani. Trigona propolis and its potency for health and healing process. Elsevier Inc; 2019.

12. M Mahani, A Sulaeman, F Anwar, MRM Damanik H, A Ploeger. Determination of Indonesian native stingless bee propolis as complementary nutraceutical candidate of an anti-tuberculosis drug. Int J Pharm 2018;4:15.

13. S Ahmed, MM Hasan, SW Ahmed, Z Alam Mahmood, I Azhar, S Habtemariam. Anti-emetic effects of bioactive natural products. Phytopharmacology 2013;2:390-433.

14. L Zheng, LK Shi, C Zhao, QZ Jin, XG Wang. Fatty acid, phytochemical, oxidative stability and in vitro antioxidant property of sea buckthorn (Hippophaë rhamnoides L.) oils extracted by supercritical and subcritical technologies. Food Sci Tech 2017;86:507-13.

15. SC Chow, JP Liu. Sample size calculations in clinical research. $2^{\text {nd }}$ ed. Chapman and Hall/CRC biostatistics series; 2008.

16. JC Herlambang Pranandaru, Adi Sembodo. Propolis sebagai suplemen bagi pasien tuberkulosis dewasa. PKM Penelitian. Dikti Kemendikbud; 2014.

17. CC Liu, JM Hsu, LK Kuo, CP Chuu. Caffeic acid phenethyl ester as an adjuvant therapy for advanced prostate cancer. Med Hypotheses 2013;5:617-9.

18. L Denholm, G Gallagher. Physiology and pharmacology of nausea and vomiting. Anaesth Intensive Care Med 2018;9:513-6.

19. CD Balaban, BJ Yates. What is nausea? A historical analysis of changing views. Auton Neurosci Basic Clin 2017;202:5-17.

20. W Zhao, Y Weng. A simplified formula for quantification of the probability of deterministic assignments in permuted block randomization. J Stat Plan Inference 2011;1:474-8.

21. ST Omaye. Food and Nutritional Toxicology; 2004.

22. MA Arbex, M de CL Varella, HR de Siqueira, FAF de Mello. Antituberculosis drugs: drug interactions, adverse effects, and use in special situations. Part 2: second-line drugs. J Bras Pneumol 2010;5:641-56.

23. A Zumla, P Nahid, ST Cole. Advances in the development of new tuberculosis drugs and treatment regimens. Nat Rev Drug Discovery 2013;5:388-404.

24. A Singh, R Prasad, V Balasubramanian, N Gupta, P Gupta. Prevalence of adverse drug reaction with first-line drugs among patients treated for pulmonary tuberculosis. Clin Epidemiol Glob Heal 2015;3:S88-90.

25. TE Chang, YS Huang, CH Chang, CL Perng, YH Huang, MC Hou. The susceptibility of anti-tuberculosis drug-induced liver injury and chronic hepatitis $\mathrm{C}$ infection: a systematic review and meta-analysis. J Chinese Med Assoc 2018;2:111-8.

26. ZH Zhang, JH Tang, ZL Zhan, XL Zhang, HH Wu, YN Hou. Cellular toxicity of isoniazid together with rifampicin and the metabolites of isoniazid on QSG-7701 hepatocytes. Asian Pac J Trop Med 2012;4:306-9.

27. P Shang. Incidence, clinical features and impact on antituberculosis treatment of anti-tuberculosis drug-induced liver injury (ATLI) in China. PLoS One 2011;7:1-7.

28. KC Chang, CC Leung, WW Yew, TY Lau, CM Tam. Hepatotoxicity of pyrazinamide: cohort and case-control analyses. Am J Respir Crit Care Med 2008;12:1391-6.

29. U Bharti, NR Kumar, J Kaur. Protective effect of bee propolis against anti-tuberculosis drugs (Rifampicin and isoniazid)induced hematological toxicity in sprague dawley rats. Asian J Pharm Clin Res 2017;3:188-90.

30. EI Ginns. A juvenile form of glycerol kinase deficiency with episodic vomiting, acidemia, and stupor. J Pediatr 1984;5:736-9.

31. DR Sjarif, JK Ploos Van Amstel, M Duran, FA Beemer, BT Poll. The isolated and contiguous glycerol kinase gene disorders: a review. J Inherit Metab Dis 2000;6:529-47.

32. OE Adelakun, T Kudanga, IR Green, M Le Roes Hill, SG Burton. Enzymatic modification of 2,6-dimethoxyphenol for the synthesis of dimers with high antioxidant capacity. Process Biochem 2012;12:1926-32.

33. QUA Shaikh. 1,2,3,4,6-Pentakis[-0-(3,4,5-trihydroxybenzoyl)]- $\alpha, \beta$ D-glucopyranose (PGG) analogs: design, synthesis, anti-tumor and anti-oxidant activities. Carbohydr Res 2016;430:72-81. 
34. BM Escribano. Dose-dependent S-allyl cysteine ameliorates multiple sclerosis disease-related pathology by reducing oxidative stress and biomarkers of dysbiosis in experimental autoimmune encephalomyelitis. Eur J Pharmacol 2017;815:266-73.

35. H Becerril Chavez. Protective effects of S-allyl cysteine on behavioral, morphological and biochemical alterations in rats subjected to chronic restraint stress: antioxidant and anxiolytic effects. J Funct Foods 2017;35:105-14.

36. LQ Lien. New naphthalene derivatives and isoquinoline alkaloids from ancistrocladus cochinchinensis with their antiproliferative activity on human cancer cells. Bioorganic Med Chem Lett 2016;16:3913-7.

37. AY Tijani, SE Okhale, FE Oga, SZ Tags, OA Salawu, BA Chindo. Anti-emetic activity of grewia lasiodiscus root extract and fractions. Afr J Biotechnol 2008;17:3011-6.

38. NT Giang An. Mosquito larvicidal activity, antimicrobial activity, and chemical compositions of essential oils from four species of myrtaceae from central Vietnam. Plants 2020;9:554.

39. J Waikedre. Antifungal activity of the essential oils of callitris neocaledonica and c. sulcata heartwood (Cupressaceae). Chem Biodivers 2012;9:644-53.

40. H Noureddine. Chemical characterization and cytotoxic activity evaluation of lebanese propolis. Biomed Pharmacother 2017;95:298-307.

41. H Yang, Z Huang, Y Huang, W Dong, Z Pan, L Wang. Characterization of Chinese crude propolis by pyrolysis-gas chromatography/mass spectrometry. J Anal Appl Pyrolysis 2015;113:158-64.

42. YQ Hu. Isoniazid derivatives and their anti-tubercular activity. Eur J Med Chem 2017;133:255-67.

43. D Erlianda, MF Rizal, and S. B. Budiardjo. Antibacterial effect of flavonoids from propolis produced by trigona on atpase activity of streptococcus mutans. Int J Appl Pharm 2017;2:6-9.
44. WP Melinda, N Soedarsono, R Farida. Effects of propolis extract and propolis candies against candida albicans ATCC 10231 growth. Asian J Pharm Clin Res 2017;10:20-2.

45. Q Wang. Physcion 8-0- $\beta$-glucopyranoside suppresses tumor growth of hepatocellular carcinoma by downregulating PIM1. Biomed Pharmacother 2017;92:451-8.

46. AC Nascimento. Antiviral activity of faramea bahiensis leaves on dengue virus type- 2 and characterization of a new antiviral flavanone glycoside. Phytochem Lett 2017;19:220-5.

47. DR Sjarif. Clinical heterogeneity and novel mutations in the glycerol kinase gene in three families with isolated glycerol kinase deficiency. J Med Genet 1998;8:650-6.

48. MS Baliga. Phytochemicals in the prevention of ethanolinduced hepatotoxicity: A revisit. Elsevier Inc; 2019

49. E Ramos Tovar, P Muriel. Phytotherapy for the liver. no 253037. Elsevier Inc; 2019.

50. J Robinson, EA Newsholme. Some properties of hepatic glycerol kinase and their relation to the control of glycerol utilization. Biochem J 1969;4:455-64.

51. DG Johnston, KGMM Alberti, R Wright, PG Blain. Glycerol clearance in alcoholic liver disease. Gut 1982;4:257-64.

52. A Sulaeman, M Mahani, H Hardinsyah, E Darma, SR Mubarokah, N Nurjanah. Hepatoprotective activity of Indonesian stingless bee propolis against toxicity of anti-tuberculosis drug on pulmonary tb patients. Apiterapi ve Doga Derg. J Apitherapy Nat 2018;3:10.

53. Z Kokanova Nedialkova, P Nedialkov, M Kondeva Burdina, R Simeonova, V Tzankova, D Aluani. Chenopodium bonus henricus L.-A source of hepatoprotective flavonoids. Fitoterapia 2017;118:13-20.

54. J Vinholes, A Rudnitskaya, P Gonçalves, F Martel, MA Coimbra, SM Rocha. Hepatoprotection of sesquiterpenoids: a quantitative structure-activity relationship (QSAR) approach. Food Chem 2014:146:78-84. 